\title{
Effects of pulse-dose ruminal infusion of butyrate on plasma glucagon-like peptide 1 and 2 concentrations in dairy calves
}

\author{
Bayissa Hatew, ${ }^{1}$ Yudai Inabu, ${ }^{1,2}$ Toshihisa Sugino, ${ }^{2}$ and Michael Steele ${ }^{1 *}$ \\ ${ }^{1}$ Department of Agricultural, Food, and Nutritional Science, University of Alberta, Edmonton, AB, T6G 2P5, Canada \\ ${ }^{2}$ Graduate School of Biosphere Science, The Research Center for Animal Sciences, Hiroshima University, Higashi-Hiroshima, \\ Hiroshima 739-8528, Japan
}

\section{ABSTRACT}

Feeding of butyrate was found to have a positive effects in enhancing gut development and improving growth performance of calves. Equally, glucagon-like peptide 1 and 2 (GLP-1 and GLP-2), secreted from gastrointestinal L-cells in response to nutrient intake, were found to play a significant role in regulating blood glucose homeostasis and improving gut health. However, limited information is available about the relationship between butyrate and release of GLP-1 and GLP-2 in dairy calves. The objective of this study was to evaluate the effects of a pulse-dose ruminal infusion of butyrate on plasma GLP-1 and GLP-2 concentrations in dairy calves. Five ruminally cannulated mature Holstein bull calves $(7.2 \pm 0.10 \mathrm{mo}$, and $330 \pm 16.0 \mathrm{~kg}$ of body weight; mean \pm standard deviation) were used in a $5 \times 5$ Latin square with 4 -d periods. On d 1 of each period at $0800 \mathrm{~h}$, calves were ruminally infused with 1 of 5 treatments: 0 (saline), 0.3, 0.6, 0.9, and $1.2 \mathrm{~g}$ of butyrate per $\mathrm{kg}$ of body weight. Before butyrate infusion, calves were not offered feed overnight, and sequential blood and rumen fluid samples were taken before and after infusion on d 1 of each period. Ruminal butyrate and total volatile fatty acid concentrations increased linearly $(2.65,12.19,20.99,30.19$, and $36.30 ; 23.68$, $33.07,40.94,51.13$, and $56.31 \mu \mathrm{mol} / \mathrm{mL}$, for butyrate and total volatile fatty acids, respectively) in a dosedependent manner, whereas propionate and isobutyrate increased quadratically. Ruminal and plasma butyrate, $\beta$-hydroxybutyrate, GLP-1, GLP-2, insulin, and glucose concentrations were all affected by treatment, time (except GLP-2), and interaction of treatment with time (except GLP-1). The area under the curve (AUC) summarized at different time points relative to the baseline (AUC30, AUC60, AUC120, and AUC240) for ruminal

Received August 21, 2018.

Accepted November 26, 2018.

*Corresponding author: masteele@uoguelph.ca and plasma butyrate, and BHB, increased linearly with the dose of butyrate infused. However, AUC30, AUC60, AUC120, and AUC240 for plasma GLP-2 concentration were affected in a cubic manner unlike the linear effect on AUC30 and AUC60 for GLP-1. Plasma GLP-2 was not correlated with plasma butyrate $(\mathrm{r}=0.16)$, GLP-1 $(r=0.03)$, or BHB $(r=-0.05)$. This findings suggest that pulse-dosing of butyrate slightly increased both GLP-1 and GLP-2 concentrations at specific time points and this might be promoted by direct or indirect effect of butyrate on the intestinal L-cells.

Key words: butyrate, infusion, glucagon-like peptide 1 , glucagon-like peptide 2 , calf

\section{INTRODUCTION}

Glucagon-like peptide 1 and 2 (GLP-1 and GLP-2) are gut-derived peptides secreted from gastrointestinal L-cells primarily from the distal intestine in parallel and in equimolar amounts in response to nutrient intake (Herrmann et al., 1995; Burrin et al., 2003; Baldassano et al., 2016). Unlike GLP-2, which mainly regulates energy and maintenance of mucosal morphology, and function and integrity of the intestine (Drucker and Yusta, 2014), GLP-1 regulates blood glucose homeostasis through its combined actions on the stimulation of glucose-dependent insulin secretion and the inhibition of glucagon secretion, gastric emptying, and food intake (Drucker, 2002).

Administration of GLP-2 has also been reported to improve gastrointestinal health of calves through its trophic actions in the gut, which include increasing small intestinal blood flow and increasing epithelial mass in the jejunum and ileum (Taylor-Edwards et al., 2011), AA utilization (Taylor-Edwards et al., 2012), promoting intestinal health and reducing infection as well as suppressing gastric motility (Wallis et al., 2007; Connor et al., 2013, 2016, 2017). Similarly, exogenous administration of GLP-1 inhibited gastric emptying and normalized blood glucose concentrations in humans (Wettergren et al., 1993; Little et al., 2006), though 
limited information is available for ruminants. Furthermore, the therapeutic potential of exogenous GLP-2 as a meaningful method for intestinal development and defense against infection during weaning in pigs has also been reported (Sigalet et al., 2014; Thymann et al., 2014).

Despite the potential benefits of GLP-1 and GLP2 , the duration of their action are limited due to a rapid inactivation of these peptides by the ubiquitous protease dipeptidyl peptidase-IV (DPP-IV). The half-life of circulating biologically active GLP-1 is less than 2 min, whereas bioactive GLP-2 has a half-life of approximately 5 to 7 min (Hartmann et al., 2000; Wallis et al., 2007). As such, it requires an extended time course to achieve desired physiological responses and necessitates daily administration (Connor et al., 2015). Besides, attaining the useful physiological range through exogenous administration of GLP-1 or GLP2 is not a feasible approach in the current dairy calf production system because of practical application and animal welfare issues.

Therefore, an alternative approach is to stimulate the release of endogenous GLP-1 and GLP-2 through the ingestion of nutrients, because nutrient intake is the primary stimulus (Burrin et al., 2003; Baldassano et al., 2016). In line with this, data showed that inclusion of lactose in calf starters resulted in higher plasma GLP-1 and GLP-2 concentrations in calves (Inabu et al., 2017). In previous studies, feeding of butyrate was shown to improve gut health and development in calves (Górka et al., 2009, 2014; Guilloteau et al., 2010). The beneficial effects of butyrate when supplemented in milk replacers and calf starters was suggested to be attributed in part to the role of butyrate in regulating GLP-2 release (Górka et al., 2009). Also, results from different animal model studies have shown that butyrate can influence other key gut hormones and peptides, such as pancreatic peptide (Kotunia et al., 2004), peptide YY (Vidrine et al., 2014; Brooks et al., 2016), glucosedependent insulinotropic polypeptide (Lin et al., 2012), gastrin (Kotunia et al., 2004; Mazzoni et al., 2008; Guilloteau et al., 2010), cholecystokinin (Kotunia et al., 2004; Guilloteau et al., 2010), and insulin (Husveth et al., 1996). Moreover, butyrate was reported to be the main secretagogue for an increase in secretion of GLP-1 and GLP-2 in sheep infused with different VFA including butyrate (Elsabagh et al., 2017). However, limited information is available about the relationship between butyrate infusion and secretion of GLP-1 and GLP-2 in dairy calves. Thus, the objective of this study was to determine the effects of pulse-dose ruminal infusion of butyrate on dynamic changes in plasma GLP-1 and GLP-2 concentrations in dairy calves. Understanding the response of GLP-1 and GLP-2 to different pulsedose infusion of butyrate may help to determine the range in which the secretion of these peptides could be stimulated by dietary interventions. We hypothesized that increasing pulse-dose infusion of butyrate would increase plasma GLP-1 and GLP-2 concentrations.

\section{MATERIALS AND METHODS}

\section{Animals and Housing}

All animal procedures undertaken were approved by the Animal Care and Use Committee: Livestock (protocol no. 00002010), University of Alberta (Edmonton, Canada). Mature Holstein bull calves were used in this study, and all calves were maintained under identical housing conditions and nutritional regimens at the Laird McElroy Environmental and Metabolic Research Centre of University of Alberta. Calves were housed in an individual pen bedded with wood shavings. Pens were cleaned once per week, but fresh shavings were added to the pens every day. Calves were fed dry TMR composed of $80 \%$ concentrate and $20 \%$ chopped straw, and fed to $10 \%$ daily refusal. The ingredient and chemical composition of the dry TMR is presented in Table 1. Calves were fed twice daily at 0700 and $1600 \mathrm{~h}$ and daily feed intake was recorded. Calves had free access to drinking water. The health status of calves was checked daily by monitoring feed intake, general behavior, and other health-indicating features (nose discharge and fecal score). Body temperature was measured when illness was suspected.

Table 1. Ingredient and nutrient composition of diet fed to calves during the experiment

\begin{tabular}{lc}
\hline Item & Composition \\
\hline Ingredient composition, \% & \\
Concentrate & 80 \\
Chopped wheat straw & 20 \\
Nutrient composition, \% of DM & \\
(unless otherwise stated) & \\
$\mathrm{DM}$ & 88.2 \\
$\mathrm{CP}$ & 18.7 \\
$\mathrm{NDF}$ & 34.0 \\
$\mathrm{ADF}$ & 18.0 \\
$\mathrm{NFC}$ & 26.8 \\
$\mathrm{ME}, \mathrm{Mcal} / \mathrm{kg}$ of DM & 2.8 \\
$\mathrm{NE}, \mathrm{Mcal} / \mathrm{kg}$ of DM & 1.3 \\
$\mathrm{NE}{ }_{\mathrm{M}}, \mathrm{Mcal} / \mathrm{kg}$ of DM & 1.9 \\
$\mathrm{Ca}$ & 0.8 \\
$\mathrm{P}$ & 0.5 \\
$\mathrm{Mg}$ & 0.3 \\
$\mathrm{~K}$ & 1.2 \\
$\mathrm{Na}$ & 0.3 \\
\hline${ }^{1} \mathrm{The}$ concentrate also contained some AA (lysine and methionine), \\
vitamins, and other minerals.
\end{tabular}
vitamins, and other minerals. 


\section{Animals, Design, and Procedures}

Five calves were ruminally cannulated during the second week of life and fitted with a $28-\mathrm{mm}$ (i.d., Lesmeister and Heinrichs, 2004) rubber ruminal cannula (Macam Rubber Pty. Ltd., Baulkham Hills, Australia). The calves were then used for a different study in our laboratory and weaned at $42 \mathrm{~d}$ of age (van Niekerk et al., 2018). The rumen cannula was switched to a 50.8mm (i. d.) rubber cannula (Bar Diamond Inc., Parma, ID) at 10 wk of age.

The calves were $7.2 \pm 0.10$ mo of age and $330 \pm 16.0$ $\mathrm{kg}$ of $\mathrm{BW}$ (mean $\pm \mathrm{SD}$ ) when enrolled in the current experiment. The experiment was conducted as a $5 \times 5$ Latin square design with 4 -d periods. The first day of each experimental period was used for sample collection and the remaining $3 \mathrm{~d}$ as a washout period before the start of the next period. This period length was chosen based on a study with cows where 3 -d periods were used (Herrick et al., 2017). On d 1 of each period at $0730 \mathrm{~h}$, calves were restrained within their pens with a halter and remained restrained until the end of sample collection time $(1300 \mathrm{~h})$. During this time calves were restricted from access to feed. At $0800 \mathrm{~h}$, calves were ruminally infused with 1 of 5 treatments: (1) 0 (saline; $\mathbf{0 B}),(2) 0.3 \mathrm{~g}$ of butyrate per $\mathrm{kg}$ of BW (3B; $0.38 \mathrm{~g}$ of sodium butyrate per $\mathrm{kg}$ of $\mathrm{BW}$ ), (3) $0.6 \mathrm{~g}$ of butyrate per $\mathrm{kg}$ of BW $(\mathbf{6 B} ; 0.76 \mathrm{~g}$ of sodium butyrate per $\mathrm{kg}$ of $\mathrm{BW})$, (4) $0.9 \mathrm{~g}$ of butyrate per $\mathrm{kg}$ of BW $(\mathbf{9 B} ; 1.14 \mathrm{~g}$ of sodium butyrate per $\mathrm{kg}$ of $\mathrm{BW}$ ), or (5) $1.2 \mathrm{~g}$ of butyrate per $\mathrm{kg}$ of $\mathrm{BW}(\mathbf{1 2 B} ; 1.52 \mathrm{~g}$ of sodium butyrate per $\mathrm{kg}$ of BW). Sodium n-butyrate (98\% pure; Sigma-Aldrich, ON, Canada) was used as the source of butyrate, and sodium chloride was added to $0 \mathrm{~B}, 3 \mathrm{~B}, 6 \mathrm{~B}$, and $9 \mathrm{~B}$ (0.81, 0.60, 0.40, and $0.20 \mathrm{~g}$ per $\mathrm{kg}$ of $\mathrm{BW}$, respectively) to balance for sodium. To calculate the accurate dose of butyrate to be infused, calves were weighed $12 \mathrm{~h}$ before the start of each period.

Treatment solutions were prepared by dissolving sodium chloride $(0 \mathrm{~B})$, sodium butyrate and sodium chloride mixture $(3 \mathrm{~B}, 6 \mathrm{~B}$, and $9 \mathrm{~B})$, or only sodium butyrate (12B) in double-distilled water on a magnetic stirrer. The final volume of the solution was adjusted to $1.5 \mathrm{~L}$ and each calf was infused ruminally with a single dose of their respective treatment at $0800 \mathrm{~h}$. Before butyrate infusion, calves were not offered feed overnight. Solutions were infused into the rumen via a rumen cannula using a Two Quart Fluid Feeder (Springer Magrath, Glencoe, MN). The solution was infused and equally distributed by placing the tube of the Fluid Feeder at 3 locations within the rumen (cranial dorsal sac, ventral, and caudal). An additional $200 \mathrm{~mL}$ of distilled water was used to rinse the Fluid Feeder bottle and infused into the rumen at the conclusion of treatment administration, and infusion was completed over 1 min. Calves had free access to fresh water during the entire duration of the experimental period.

To facilitate ease of serial collection of blood, approximately $14 \mathrm{~h}$ before the start of each period, the external jugular vein catheter was inserted for each calf. The catheter tubing was made in our laboratory from Tygon Tubing (Saint Gobain Performance Plastics Tygon Microbore Formula S-54-HL, Fisher Scientific, Ottawa, Ontario, Canada). A white adhesive tape and crazy glue were used to secure the base of the catheter to the skin. A MicroClave extension set (ICU Medical Inc., San Clemente, CA) was attached to the catheter and flushed with sodium heparin $(20 \mathrm{IU} / \mathrm{mL})$ to prevent clotting of blood. A veterinary wrap (Vetwrap, Veterinarians Choice, Calgary, Canada) was used to wrap the catheter and extension around the neck of the animal. Finally, a piece of Elastoplast tape [BSN Medical, Laval (QC), Canada] was wrapped around the Vetwrap to ensure the Vetwrap stayed in place around the catheter and extension set.

\section{Sample Collection}

Ruminal fluid sample for each calf was collected via rumen cannula from 3 different regions of the rumen (the front ventral, middle ventral, and cranial dorsal sac) before (-15 min) and after $(30,60,120,180,240$, and $300 \mathrm{~min}$ ) butyrate infusion. Samples were collected by suction method using a plastic tube $(0.65 \mathrm{~m}$ long and $0.25 \mathrm{~cm}$ i.d.) attached to a 1-L plastic bottle. Rumen fluid samples obtained from these 3 different regions of the rumen were pooled and $10 \mathrm{~mL}$ of rumen fluid sample was transferred into a $15-\mathrm{mL}$ sampling tube and immediately frozen in liquid nitrogen. The remaining rumen fluid was placed back into the rumen, and samples were stored at $-20^{\circ} \mathrm{C}$ until further analysis.

Blood samples were withdrawn immediately before $(-30$ and $-15 \mathrm{~min})$ and after $(5,10,15,20,25,30,40$, $50,60,90,120,150,180,240$, and $300 \mathrm{~min}$ ) butyrate infusion through the catheter using a 10-mL Luer-Lok tip syringe (BD Luer-Lok disposable syringes, Thermo Fisher Scientific, Mansfield, MA). Blood samples were immediately transferred into tubes containing sodium heparin (BD Vacutainer, Franklin Lakes, NJ), placed on ice, treated with aprotinin $(0.01 \mathrm{mg} / \mu \mathrm{L}$; Sigma, St. Louis, MO), and centrifuged at $3,000 \times g$ at $4^{\circ} \mathrm{C}$ for 20 min. Then, plasma was removed and stored at $-20^{\circ} \mathrm{C}$ until assayed for butyrate, BHB, GLP-1, GLP-2, insulin, and glucose content.

At the end of sample collection time (1300 h) for each period, calves were released from restraints and given access to feed. 


\section{Sample Analysis}

Rumen fluid samples were thawed, centrifuged at $2,000 \times g$ for $20 \mathrm{~min}$ at $4^{\circ} \mathrm{C}$, and supernatant was collected and mixed with $25 \%$ meta-phosphoric acid (4:1; $\mathrm{vol} / \mathrm{vol}$ ) and immediately frozen in $-20^{\circ} \mathrm{C}$ until needed for VFA analysis. Concentrations of short-chain fatty acids were measured by GC (Varian 430, Palo Alto, $\mathrm{CA})$ equipped with a flame ionization detector $\left(250^{\circ} \mathrm{C}\right)$ fitted with a DB-FFAP column $(30 \mathrm{~m}, 0.53 \mathrm{~mm}$ i.d., 0.5 $\mu \mathrm{m} \mathrm{df})$. Helium gas was a carrier at constant flow of $20 \mathrm{~mL} / \mathrm{min}$. Oven temperature was initially set at $80^{\circ} \mathrm{C}$ and gradually increased to $210^{\circ} \mathrm{C}$ at a rate of $45^{\circ} \mathrm{C} / \mathrm{min}$. A total GC runtime of 8 min was used for each sample.

Plasma butyrate was analyzed with the same procedure and equipment as previously described for analysis of ruminal fluid VFA. The BHB concentration was measured by the enzymatic oxidation of BHB to acetoacetate using 3-hydroxybutyrate dehydrogenase (Roche, Mississauga, ON, Canada) followed by determination of reduction of $\mathrm{NAD}^{+}$to $\mathrm{NADH}$ at a wavelength of $340 \mathrm{~nm}$ on a SpectraMax 384 Plus Microplate Reader (Molecular Devices, San Jose, CA).

Plasma hormone (GLP-1, GLP-2, and insulin) concentrations were measured following the time-resolved fluoroimmunoassay technique, which was previously described by Sugino et al. (2004). Plasma GLP-1 concentration was measured using a solid-phase competition immunoassay with europium (Eu)-labeled human GLP-1 and polystyrene microtiter strips (Nalgene Nunc Int., Tokyo, Japan) coated with anti-rabbit $\gamma$-globulin (Inabu et al., 2017). Intra- and interassay CV were 4.4 and $4.8 \%$, respectively, and the least detectable level was $0.008 \mathrm{ng} / \mathrm{mL}$. Plasma GLP-2 concentrations was measured using a solid-phase competition immunoassay with Eu-labeled human GLP-2 (Elsabagh et al., 2017; Inabu et al., 2017). The plasma concentration of insulin was measured using a solid-phase competition immunoassay with Eu-labeled bovine insulin and polystyrene microtiter strips coated with anti-guinea pig $\gamma$-globulin (Inabu et al., 2017). Intra- and interassay coefficients of variation for insulin were 3.1 and $2.6 \%$, respectively, and the least detectable level was $0.24 \mathrm{ng} / \mathrm{mL}$.

Plasma glucose concentration was analyzed using an enzymatic method using glucose oxidase and peroxidase enzyme (Sigma, St. Louis, MO). Absorbance was determined by a plate reader (SpectraMax 190) at a wavelength of $450 \mathrm{~nm}$.

\section{Statistical Analysis}

Data were analyzed using the MIXED procedure of SAS version 9.4 (SAS Institute Inc., Cary, NC) where the model included fixed effect of period, square, treatment, time and interaction of treatment with time, and the random effect of calf within square. The REML method was used to estimate least squares means, and the Kenward-Roger method was used to calculate denominator degrees of freedom. The covariance structure used to fit the model was selected based on the Akaike's information criterion of the mixed models of SAS (Littell et al., 2006). For plasma hormones and metabolites, and ruminal fluid and plasma VFA, time was considered the repeated measure and analyzed by the repeated measures of ANOVA by taking repeated samples within the same calf into account. The effect of time and its interaction with treatment were tested with the within-subject residual error term. Because of the unequally spaced sampling times, a spatial power variance component was used as the covariance structure of choice.

The area under the curve (AUC) was calculated using the trapezoid rule and was calculated over the entire sampling period. The sums of squares due to treatment (pulse-dose of butyrate infusion) were further partitioned into orthogonal polynomial contrasts (linear, quadratic, and cubic) using the CONTRAST statement of SAS. In addition, Pearson correlation coefficients were performed to characterize the relationship between GLP-2, plasma butyrate, BHB, GLP-1, insulin, and glucose concentrations. Least squares means and standard error of the means are reported throughout with a statistical significance declared at $P$ $\leq 0.05$ and a tendency discussed at $0.05<P \leq 0.10$.

\section{RESULTS}

\section{Diet and Feeding}

Chemical composition of the diet used in this experiment is shown in Table 1. Calves consumed $7.8 \pm 0.88$ $\mathrm{kg}$ of $\mathrm{DM} / \mathrm{d}$ (mean $\pm \mathrm{SD}$ ) during the experiment. All calves were fed the same diet before and during the experimental time.

\section{Ruminal Fermentation}

Ruminal VFA concentration in response to increasing pulse-dose intraruminal butyrate infusion is presented in Table 2. Concentrations of butyrate $(P<0.001)$ and total VFA $(P<0.001)$ increased linearly in a dosedependent manner, whereas a quadratic effect was observed for propionate $(P=0.047)$ and isobutyrate $(P$ $=0.040)$. Isovalerate showed a tendency $(P=0.063)$ to increase linearly with the increase in the dose of butyrate infusion. However, acetate and valerate con- 
Table 2. Effect of intraruminal pulse-dose infusion of butyrate on ruminal VFA concentrations of dairy calves ${ }^{1}$

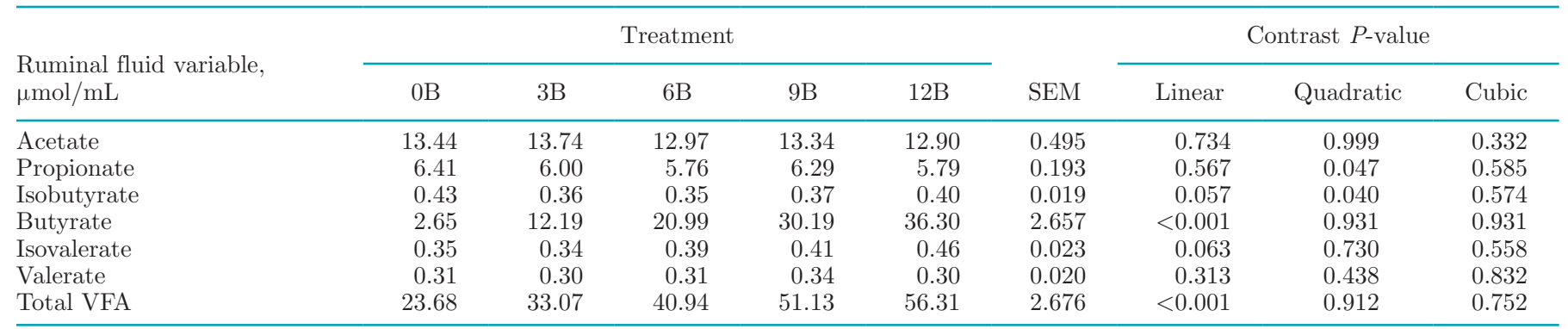

${ }^{1}$ Calves were ruminally infused with saline (0B), $0.3 \mathrm{~g}$ of butyrate per $\mathrm{kg}$ of BW (3B; $0.38 \mathrm{~g}$ of sodium butyrate per kg of BW), $0.6 \mathrm{~g}$ of butyrate per $\mathrm{kg}$ of BW (6B; $0.76 \mathrm{~g}$ of sodium butyrate per $\mathrm{kg}$ of $\mathrm{BW}), 0.9 \mathrm{~g}$ of butyrate per $\mathrm{kg}$ of $\mathrm{BW}$ (9B; $1.14 \mathrm{~g}$ of sodium butyrate per $\mathrm{kg}$ of BW), and $1.2 \mathrm{~g}$ of butyrate per $\mathrm{kg}$ of BW (12B; $1.52 \mathrm{~g}$ of sodium butyrate per $\mathrm{kg}$ of $\mathrm{BW}$ ) on $\mathrm{d} 1$ of each period at $0800 \mathrm{~h}$. Ruminal fluid samples were collected before (0 min) and after $(30,60,120,180,240$, and $300 \mathrm{~min})$ butyrate infusion. Data are expressed as the LSM \pm SEM, which represents the pooled SE for the model.

centrations remained unaffected by the treatments. Furthermore, the concentrations of individual ruminal VFA, except isovalerate, were affected by time (Table $3 ; P<0.001)$. Unlike butyrate, the concentrations of acetate, isobutyrate, propionate, and valerate decreased with time. Similar to acetate, propionate, isobutyrate, and valerate, the concentration of isovalerate was not affected by the interaction of treatment with time. However, butyrate and total VFA concentrations were affected by both time $(P<0.001)$ and the interaction of treatment with time $(P<0.001)$.

\section{Metabolites and Hormones}

The effect of butyrate infusion on changes in metabolite and hormone concentrations is presented in Figures 1 and 2. There were an effect of time and interaction of treatment with time on ruminal (Figure 1A; $P<$ 0.001 ) and plasma (Figure 1B; $P<0.001$ ) butyrate, and BHB (Figure 1C; $P \leq 0.001$ ). Ruminal butyrate concentration increased to a higher level $30 \mathrm{~min}$ after infusion for other treatments except $0 \mathrm{~B}$ and $12 \mathrm{~B}$, which did not change until $240 \mathrm{~min}(0 \mathrm{~B})$ and reached the highest concentration at $60 \mathrm{~min}(12 \mathrm{~B})$. Calves infused with $12 \mathrm{~B}$ had ruminal butyrate of $60 \mathrm{mM}$ at $60 \mathrm{~min}$ after infusion, whereas calves infused with $0 \mathrm{~B}$ had stable ruminal butyrate concentrations, though they showed an increase at 240 min after infusion. Plasma butyrate levels of other treatments except $0 \mathrm{~B}$ increased between 5 and $10 \mathrm{~min}$ after butyrate infusion and shortly returned to baseline values. Contrary to ruminal butyrate, BHB was increased to the highest level in less than 30 min except for $9 \mathrm{~B}$ and $12 \mathrm{~B}$ and increased in a dose-dependent manner. The butyrate levels used in the current study did not cause a significant change in the plasma acetate and propionate concentrations (data not shown).

Regardless of dietary treatments, plasma GLP-1 concentration was affected by treatment and time (Figure $2 \mathrm{~A} ; P<0.001)$, but not by interaction of treatment with time. On the contrary, GLP-2 was affected only by treatment $(P<0.001)$, but not by time and interaction

Table 3. Effect of intraruminal pulse-dose infusion of butyrate on changes in ruminal VFA concentrations of dairy calves ${ }^{1}$

\begin{tabular}{|c|c|c|c|c|c|c|c|c|c|c|}
\hline \multirow{2}{*}{$\begin{array}{l}\text { Rumen fluid variable, } \\
\mu \mathrm{mol} / \mathrm{mL}\end{array}$} & \multicolumn{7}{|c|}{ Time, min } & \multirow[b]{2}{*}{ SEM } & \multicolumn{2}{|r|}{$P$-value } \\
\hline & 0 & 30 & 60 & 120 & 180 & 240 & 300 & & Time & Treatment $\times$ time \\
\hline Acetate & 16.61 & 14.82 & 13.91 & 12.93 & 11.63 & 11.70 & 11.50 & 0.495 & $<0.001$ & 0.979 \\
\hline Propionate & 7.34 & 6.62 & 6.29 & 5.95 & 5.38 & 5.49 & 5.37 & 0.265 & $<0.001$ & 0.774 \\
\hline Isobutyrate & 0.47 & 0.41 & 0.37 & 0.37 & 0.35 & 0.35 & 0.35 & 0.032 & 0.009 & 0.727 \\
\hline Butyrate & 4.70 & 29.46 & 28.52 & 25.42 & 20.17 & 17.15 & 16.83 & 2.642 & $<0.001$ & $<0.001$ \\
\hline Isovalerate & 0.37 & 0.42 & 0.39 & 0.41 & 0.37 & 0.39 & 0.37 & 0.042 & 0.880 & 0.874 \\
\hline Valerate & 0.44 & 0.37 & 0.35 & 0.30 & 0.26 & 0.25 & 0.23 & 0.026 & $<0.001$ & 0.666 \\
\hline Total VFA & 30.09 & 52.28 & 49.96 & 45.53 & 38.31 & 35.47 & 34.78 & 2.755 & $<0.001$ & $<0.001$ \\
\hline
\end{tabular}

${ }^{1}$ Calves were ruminally infused with saline (0B), $0.3 \mathrm{~g}$ of butyrate per $\mathrm{kg}$ of BW (3B; $0.38 \mathrm{~g}$ of sodium butyrate per kg of BW), $0.6 \mathrm{~g}$ of butyrate

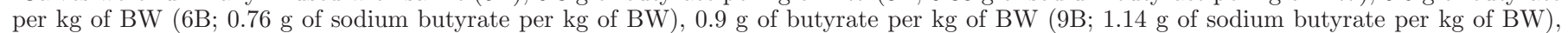

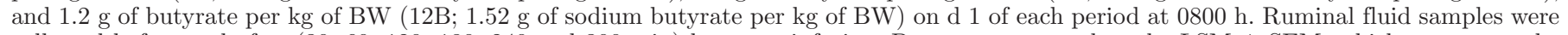

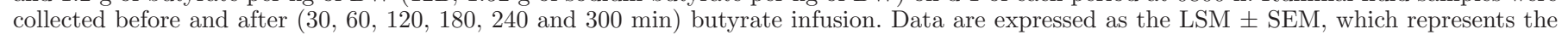
pooled SE for the model. 
of treatment with time (Figure 2B). Basal GLP-2 level for treatment $3 \mathrm{~B}$ and $6 \mathrm{~B}$ was significantly higher and lower, respectively, than other treatments. The relative
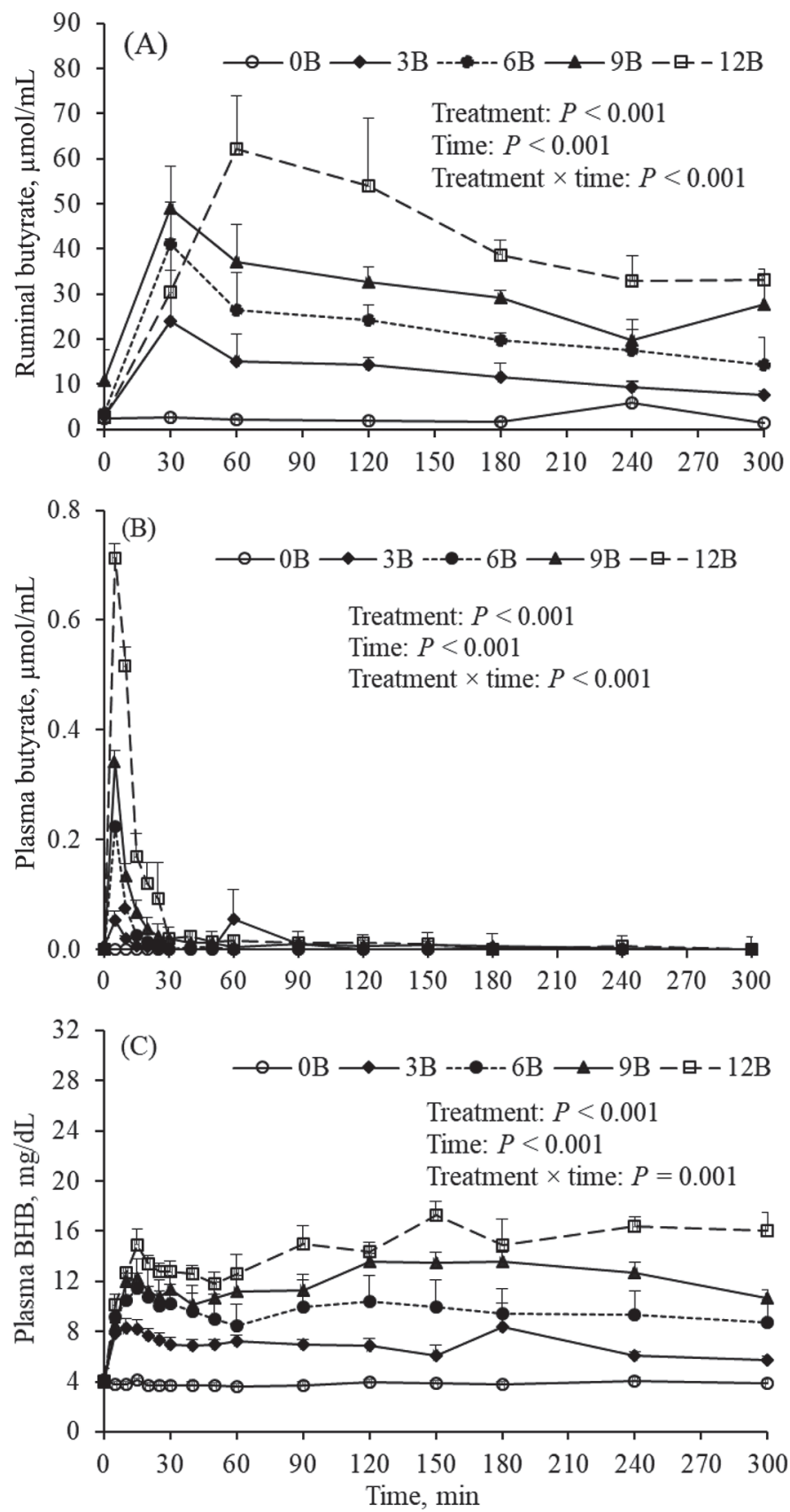

Figure 1. Effect pulse-dose intraruminal infusion of butyrate on ruminal butyrate $(\mathrm{A})$, plasma butyrate $(\mathrm{B})$, and plasma BHB (C) concentrations in dairy calves. On d 1 of each period at $0800 \mathrm{~h}$, calves were ruminally infused with saline $(0 \mathrm{~B}), 0.3 \mathrm{~g}$ of butyrate per $\mathrm{kg}$ of BW (3B; $0.38 \mathrm{~g}$ of sodium butyrate per $\mathrm{kg}$ of $\mathrm{BW}$ ), $0.6 \mathrm{~g}$ of butyrate per $\mathrm{kg}$ of $\mathrm{BW}(6 \mathrm{~B} ; 0.76 \mathrm{~g}$ of sodium butyrate per $\mathrm{kg}$ of $\mathrm{BW}), 0.9 \mathrm{~g}$ of butyrate per $\mathrm{kg}$ of $\mathrm{BW}(9 \mathrm{~B} ; 1.14 \mathrm{~g}$ of sodium butyrate per $\mathrm{kg}$ of $\mathrm{BW})$, and $1.2 \mathrm{~g}$ of butyrate per $\mathrm{kg}$ of $\mathrm{BW}(12 \mathrm{~B} ; 1.52 \mathrm{~g}$ of sodium butyrate per $\mathrm{kg}$ of $\mathrm{BW})$. Data are presented as LSM $\pm \operatorname{SEM}(\mathrm{n}=5)$. increase of plasma GLP-2 concentration after infusion was higher for 3B compared with other treatments starting from 30 min relative to time of infusion. This variation remains relatively the same until the end of sampling time (300 $\mathrm{min})$. However, GLP-2 concentrations were higher $(P=0.001)$ for $12 \mathrm{~B}$ compared with other treatments $10 \mathrm{~min}$ after infusion $(2.72$ vs. 1.82 , $2.29,1.18$, and $1.63 \mathrm{ng} / \mathrm{mL} ; 12 \mathrm{~B}$ vs. $0 \mathrm{~B}, 3 \mathrm{~B}, 6 \mathrm{~B}$, and $9 \mathrm{~B}$, respectively) even if its basal level is only higher and lower as compared with $6 \mathrm{~B}$ and $3 \mathrm{~B}$, respectively. However, analysis of the baseline data shows differences in the baseline $(P=0.001)$. Therefore, considering changes relative to the baseline and re-analyzing the data showed a linear effect of treatment on GLP-2 during 30 to $60 \mathrm{~min}(-0.15,0.04,-0.08,0.34$, and 0.56 for $0 \mathrm{~B}, 3 \mathrm{~B}, 6 \mathrm{~B}, 9 \mathrm{~B}$, and $12 \mathrm{~B}$, respectively, $P=0.017$ ), no change in GLP-2 during the early phase $(5-25 \mathrm{~min})$, and a tendency of a quadratic effect during 90 to 300 $\min (0.11,-0.01,0.06,0.25,0.31$, and 0.14 for $0 \mathrm{~B}, 3 \mathrm{~B}$, $6 \mathrm{~B}, 9 \mathrm{~B}$, and $12 \mathrm{~B}$, respectively, $P=0.094)$.

The AUC summarized at different time points (AUC30, AUC60, AUC120, and AUC240) within treatments is presented in Table 4. The AUC for ruminal butyrate (AUC30, $P<0.001$; AUC60, $P<0.001$; AUC120, $P<0.001$; and AUC240, $P<0.001)$, plasma butyrate (AUC30, $P=0.013$; AUC60, $P=0.009$; AUC120, $P=0.015$; and AUC240, $P=0.008)$, and BHB (AUC30, AUC60, AUC120, and AUC240; $P<$ $0.001)$ increased linearly in a dose-dependent manner. For GLP-1, AUC30 $(P=0.001)$ and AUC60 $(P=$ 0.011 ) were linearly affected by treatment and showed a tendency $(P=0.091)$ to increase quadratically for AUC120. On the other hand, no treatment effect was observed for AUC240. Plasma GLP-2 concentration (AUC30, $P=0.009 ;$ AUC60, $P=0.004 ;$ AUC120, $P$ $=0.009$; and AUC240, $P=0.013)$ increased in a cubic manner with dose of infusion.

On the other hand, insulin (Figure 2C) and glucose (Figure 2D) concentrations were affected by treatment $(P<0.001)$ and time $(P<0.001)$. Unlike GLP-1, plasma insulin and glucose concentration were also affected by interaction of treatment and time $(P<0.001)$. Insulin concentration was significantly elevated to the highest level 5 min after infusion for all treatment except $0 \mathrm{~B}$, and gradually decreased until 50 min before returning to a stable concentration where the difference between treatments was eliminated. Glucose concentration was elevated at $10 \mathrm{~min}$ for 12B and decreased until $50 \mathrm{~min}$ before it started increasing again. In contrast, glucose concentration decreased just after infusion for $6 \mathrm{~B}$ and 9B until 40 min and increased until 120 min and stayed at almost a constant concentration until 300 min. However, no change was observed for 0B. 

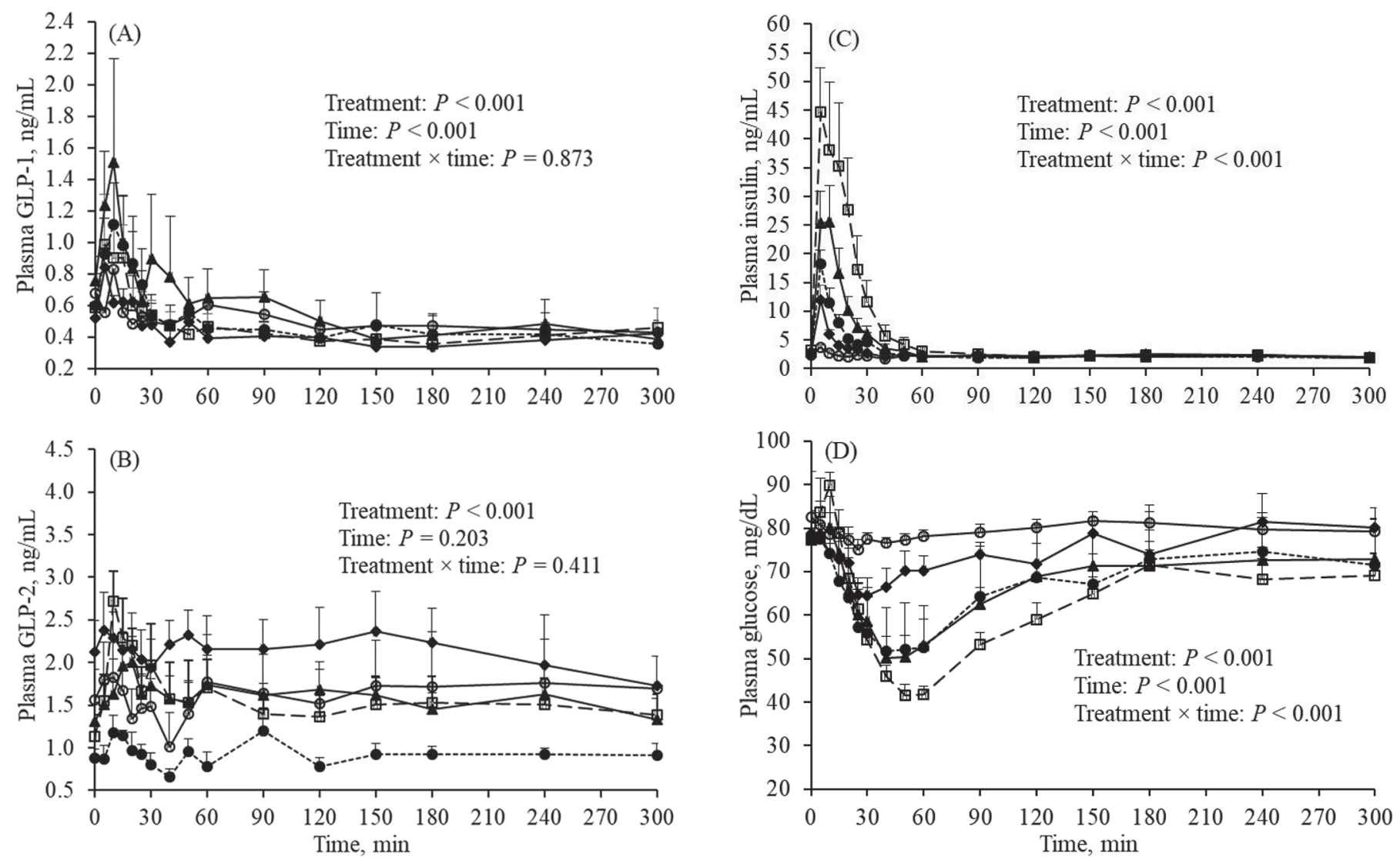

Figure 2. Effect pulse-dose intraruminal infusion of butyrate on plasma glucagon-like peptide 1 (GLP-1; A), GLP-2 (B), insulin (C), and glucose (D) concentrations in dairy calves. On d 1 of each period at $0800 \mathrm{~h}$, calves were ruminally infused with saline $(0 \mathrm{~B}), 0.3 \mathrm{~g}$ of butyrate per $\mathrm{kg}$ of BW (3B; $0.38 \mathrm{~g}$ of sodium butyrate per $\mathrm{kg}$ of BW), $0.6 \mathrm{~g}$ of butyrate per $\mathrm{kg}$ of BW (6B; $0.76 \mathrm{~g}$ of sodium butyrate per kg of BW), $0.9 \mathrm{~g}$ of butyrate per $\mathrm{kg}$ of $\mathrm{BW}(9 \mathrm{~B} ; 1.14 \mathrm{~g}$ of sodium butyrate per $\mathrm{kg}$ of $\mathrm{BW}$ ), and $1.2 \mathrm{~g}$ of butyrate per $\mathrm{kg}$ of BW (12B; $1.52 \mathrm{~g}$ of sodium butyrate per $\mathrm{kg}$ of BW). Data are presented as LSM \pm SEM $(\mathrm{n}=5)$.

Correlations of plasma GLP-1 and GLP-2 concentration with other metabolites and hormone are presented in Table 5. Positive correlation existed between GLP-1 and plasma butyrate $(\mathrm{r}=0.53 ; P<0.001)$ and insulin $(\mathrm{r}=0.67 ; P<0.001)$. However, a positive correlation was detected between GLP-2 and glucose $(\mathrm{r}=0.27 ; P=$ $0.018)$, GLP-2 and insulin ( $\mathrm{r}=0.25 ; P=0.023)$, plasma butyrate and glucose $(\mathrm{r}=0.27 ; P=0.016)$, and glucose and insulin $(\mathrm{r}=0.23 ; P=0.036)$. Similarly, a positive correlation was observed between BHB and insulin (r $=0.30 ; P=0.008)$ and plasma butyrate and insulin $(\mathrm{r}$ $=0.89 ; P<0.001)$. However, no correlation was found between GLP-1 and GLP-2, GLP-1 and BHB, GLP-2 and BHB, and GLP-2 and plasma butyrate.

\section{DISCUSSION}

Butyrate has been shown to regulate the release of different gut peptides and hormones in different mam- malian species, such as pancreatic peptide (Kotunia et al., 2004), peptide YY (Vidrine et al., 2014; Brooks et al., 2016), glucose-dependent insulinotropic polypeptide (Lin et al., 2012), gastrin (Kotunia et al., 2004; Mazzoni et al., 2008; Guilloteau et al., 2010), cholecystokinin (Kotunia et al., 2004; Guilloteau et al., 2010), and insulin (Husveth et al., 1996). However, evidence on the effect of exogenous butyrate on GLP-1 and GLP-2 in dairy calves is scant. In this study, we examined the effects of pulse-dose intraruminal infusion of butyrate on changes in plasma GLP-1 and GLP-2 concentrations in mature Holstein bull calves. Results from the present study shows that butyrate stimulates GLP-1 and GLP2 release into the circulation. Both GLP-1 and GLP-2 were found to be secreted in a biphasic pattern, with a short early peak (within 5-15 min) followed by a larger biological and significant response in the second phase (30-60 min) after infusion of butyrate. It is probable that the early phase is due to the stimulation of L-cells 
Table 4. Area under the curve (AUC) summarized at different time points for ruminal butyrate, and plasma butyrate, BHB, glucagon-like peptide 1 (GLP-1), and GLP-2 concentrations in dairy calves intraruminally infused with different pulse-dose of butyrate ${ }^{1}$

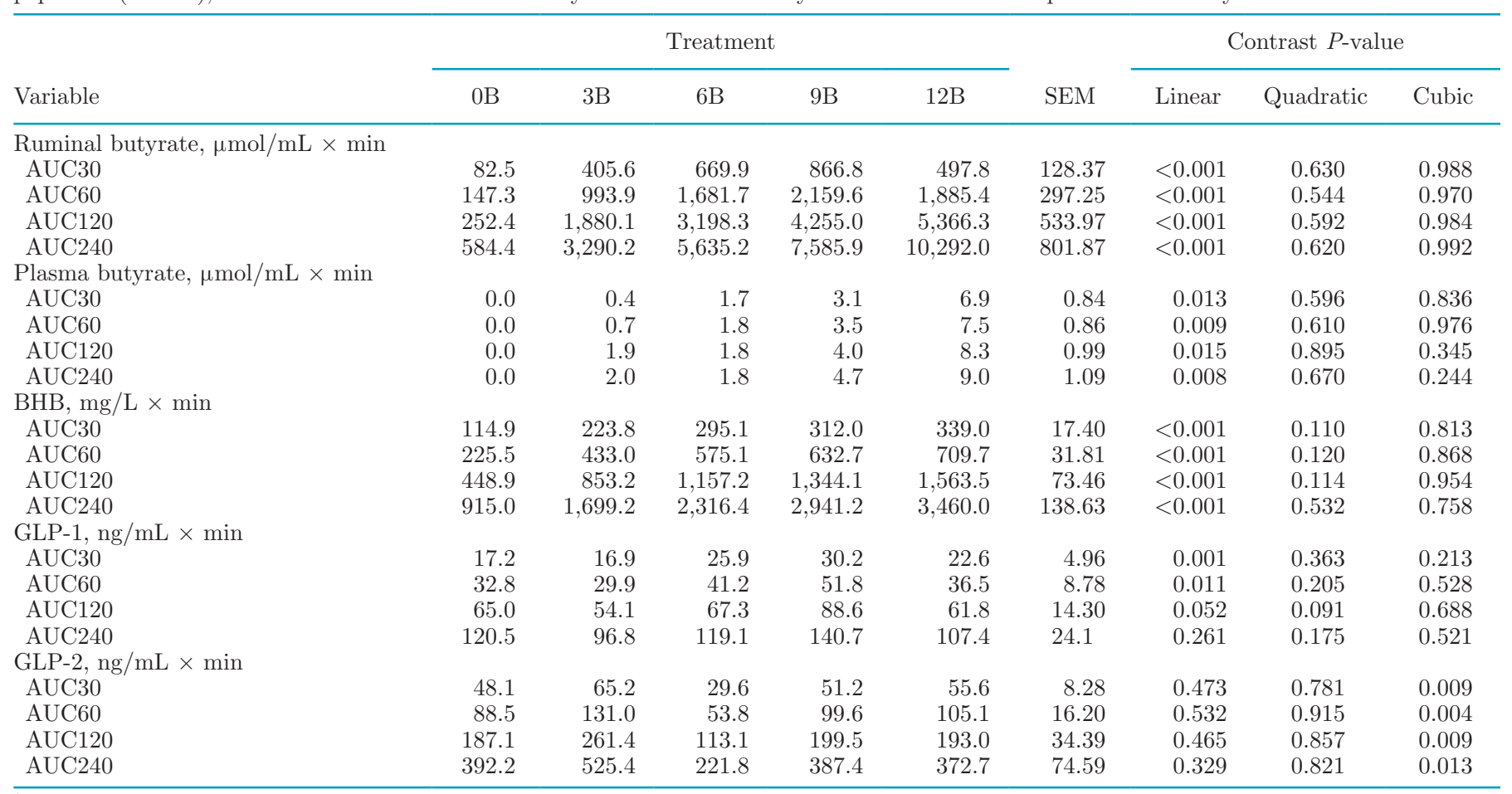

${ }^{1}$ Calves were ruminally infused with saline (0B), $0.3 \mathrm{~g}$ of butyrate per $\mathrm{kg}$ of $\mathrm{BW}$ (3B; $0.38 \mathrm{~g}$ of sodium butyrate per kg of BW), $0.6 \mathrm{~g}$ of butyrate per $\mathrm{kg}$ of BW (6B; $0.76 \mathrm{~g}$ of sodium butyrate per $\mathrm{kg}$ of $\mathrm{BW}), 0.9 \mathrm{~g}$ of butyrate per $\mathrm{kg}$ of $\mathrm{BW}(9 \mathrm{~B} ; 1.14 \mathrm{~g}$ of sodium butyrate per kg of BW), and $1.2 \mathrm{~g}$ of butyrate per $\mathrm{kg}$ of BW (12B; $1.52 \mathrm{~g}$ of sodium butyrate per $\mathrm{kg}$ of BW) on $\mathrm{d} 1$ of each period at $0800 \mathrm{~h}$. AUC30 = area under the concentration-time curve until $30 \mathrm{~min}$; AUC60 = area under the concentration-time curve from 30 to 60 min; AUC120 = area under the concentration-time curve from 60 to $120 \mathrm{~min}$; AUC240 = area under the concentration-time curve from 120 to 300 min. Data are expressed as the LSM \pm SEM, which represents the pooled SE for the model.

by butyrate through involvement of various neural and endocrine factors, in contrast with the second or late phase, which is caused by direct stimulation of intestinal L-cells by indigested butyrate, which is in agreement with a previous study (Burrin et al., 2003). Our study also demonstrated that intraruminal infusion of butyrate increased ruminal and plasma butyrate, BHB, and insulin concentrations.
However, unlike GLP-1, a large variation in baseline plasma GLP-2 concentration was noticed in the current study. These difference could be due to 2 reasons. First, the blood sample in the current study was withdrawn without controlling the migrating motor complex in the small intestine. Migrating motor complex is well characterized by the appearance of gastrointestinal contractions in the interdigestive state (Takahashi,

Table 5. Pearson correlation coefficient of plasma glucagon-like peptide 1 (GLP-1), GLP-2, BHB, butyrate, glucose, and insulin concentrations in dairy calves intraruminally infused with a different pulse-dose of butyrate ${ }^{1}$

\begin{tabular}{|c|c|c|c|c|c|}
\hline \multirow[b]{2}{*}{ Item } & \multicolumn{5}{|c|}{ Pearson correlation coefficient $(\mathrm{n}=80)^{2}$} \\
\hline & GLP-2 & BHB & Butyrate & Glucose & Insulin \\
\hline GLP-2 & & $-0.05(0.665)$ & $0.16(0.149)$ & $0.27(0.018)$ & $0.25(0.023)$ \\
\hline BHB & & & $0.19(0.089)$ & $-0.50(<0.001)$ & $0.30(0.008)$ \\
\hline Butyrate & & & & $0.27(0.016)$ & $0.89(<0.001)$ \\
\hline Glucose & & & & & $0.23(0.036)$ \\
\hline
\end{tabular}

${ }^{1}$ On d 1 of each period at $0800 \mathrm{~h}$, calves were ruminally infused with saline (0B), $0.3 \mathrm{~g}$ of butyrate per $\mathrm{kg}$ of BW (3B; $0.38 \mathrm{~g}$ of sodium butyrate per $\mathrm{kg}$ of $\mathrm{BW}), 0.6 \mathrm{~g}$ of butyrate per $\mathrm{kg}$ of $\mathrm{BW}(6 \mathrm{~B} ; 0.76 \mathrm{~g}$ of sodium butyrate per $\mathrm{kg}$ of $\mathrm{BW}$ ), $0.9 \mathrm{~g}$ of butyrate per $\mathrm{kg}$ of $\mathrm{BW}$ (9B; $1.14 \mathrm{~g}$ of sodium butyrate per $\mathrm{kg}$ of $\mathrm{BW}$ ), and $1.2 \mathrm{~g}$ of butyrate per $\mathrm{kg}$ of $\mathrm{BW}(12 \mathrm{~B} ; 1.52 \mathrm{~g}$ of sodium butyrate per $\mathrm{kg}$ of $\mathrm{BW}$ ).

${ }^{2}$ Numbers in parentheses show the $P$-value. 
2012). This may result in physiological fluctuations of gut hormones in the blood plasma, in particular before butyrate infusion, and presumably also after administration of butyrate. Second, either GLP-2 synthesis and release rates or clearance rates, or both, vary from calf to calf. This variability in synthesis could in turn be due to the total number of L-cells, which could be related to intestinal mass and L-cell density. Alternatively, clearance is proportional to the amount of DPP-IV secreted into circulation and renal clearance once secreted from the intestinal L-cells (Tavares et al., 2000; Rowland and Brubaker, 2011). We cannot rule out the possibility that these might have contributed to the effects of treatment on GLP-2 especially during the earlier phase. The effect of butyrate was not observed in the early phase when considering relative changes to the baseline, but a significant linear response of GLP-2 occurred in the second phase (30-60 min).

All the treatments were pulse-dosed and a small portion of the butyrate, especially with the high dose, might have entered the fluid portion of the rumen, subsequently getting absorbed postruminally. In lactating dairy cows it is estimated that passage from the rumen contributed 20 to $35 \%$ of total VFA produced in the rumen (Dijkstra et al., 1993). If similar situation occurred in the present study, the butyrate may have acted as a ligand on L-cells and stimulated GLP-2 release. In line with this, Górka et al. (2017) reported that butyrate flow to the duodenum tended to linearly increase with an increasing dose of exogenous butyrate $(15-45 \mathrm{~g} / \mathrm{d}$ of butyric acid) delivered to the rumen of sheep. The increase in flow of this short-chain VFA to the lower gut could stimulate gut hormone secretion through VFA receptors (free fatty acid receptors, FFA2 and FFA3), which are mainly expressed in the enteroendocrine Lcells (Karaki et al., 2006, 2008). Most of the butyrate infused in the current study might have been absorbed in the rumen since these calves were mature and ruminating when involved in the study and very little butyrate flowed out of the rumen into the abomasum. However, we anticipate that a small portion of the butyrate might have bypassed along with ruminal fluid or as microbial DM into the abomasum, although ruminal passage rate was not measured in this study.

On the other hand, early studies (Elsabagh et al., 2017; Inabu et al., 2017) suggested that the increase in GLP-1 and GLP-2 is associated with BHB produced by the rumen epithelial metabolism of butyrate. However, in our study plasma BHB was not correlated with either plasma GLP-1 or GLP-2 levels, showing that BHB produced by rumen epithelial metabolism of butyrate is likely not the cause for an increase in plasma GLP-1 or GLP-2 concentration in our experimental model, which is incompatible with the speculations of Elsabagh et al. (2017) and Inabu et al. (2017). Even though enteroendocrine butyrate-sensing is the subject of intense interest in other animal models including humans (Gao et al., 2009), little is known in ruminants regarding the molecular mechanism by which butyrate affects GLP-1 and GLP-2, a mechanism that was not addressed in the present study. Using a lipid-encapsulated butyrate increased rumen bypass butyrate and had more beneficial effects on gut health and growth in calves than a butyrate salt that would be digested and absorbed in the rumen (Górka et al., 2014). The same authors explained that these beneficial effects may be attributed in part to the role of butyrate in regulating GLP-2 release. Therefore, future study to determine the mode of feeding (ruminal infusion of protected butyrate or direct infusion of butyrate into the duodenum) and signaling mechanisms responsible for butyrate beneficial effects may reveal new strategies for stimulating adaptations using a modification of the diet rather than the administration of exogenous GLP-1 and GLP-2.

Although GLP-1 and GLP-2 are reported to be produced and secreted together primarily from L-cells of the intestine in response to ingestion of nutrients (Burrin et al., 2003) and are thought to be secreted in a 1:1 ratio (Orskov et al., 1986), our data show that GLP-1 and GLP-2 are available in the circulation in different proportions and are affected differently by the same treatment. For instance, a change in dose of butyrate infusion from $3 \mathrm{~B}$ to $12 \mathrm{~B}$ showed a $66 \%$ increase in ruminal butyrate concentration as compared with a $93 \%$ increase in plasma GLP-2 (30-60 min) concentration, but no difference in GLP-1. In addition, we did not find a correlation between GLP-1 and GLP-2. Another explanation could be due to the rate of degradation that is a significant factor in determining the levels of these peptides to be available circulating in the blood and thus determine their biological activities. As such, the half-life of circulating biologically active GLP-1 is less than 2 min (Deacon et al., 1995), whereas GLP-2 is relatively longer, with a half-life of approximately 5 to 7 min (Hartmann et al., 2000; Tavares et al., 2000). The relatively short circulating half-life of the bioactive form of GLP-1 makes it susceptible to DPP-IV degradation, and GLP-1 leaves the intestine as an inactive hormone. In contrast, GLP-2 with relatively longer half-life will leave the gut as the active form with all of the newly released GLP-2 and enters into plasma and is available in higher concentrations as compared with GLP-1. This study, to our knowledge, is the first showing such a dynamic difference in the secretion of plasma GLP-1 and GLP-2 in dairy calves and warrants further investigations. 
Ruminal individual VFA and total VFA concentrations were in the physiological range, except after butyrate infusion. The latter is associated with a rapid, up to 6 -fold, rise in the concentration of butyrate during the first 30 min after the infusion, which agrees with the results of Kowalski et al. (2015). Contrary to ruminal butyrate, which is elevated 30 min after infusion and remains elevated for a longer period, plasma butyrate peaked to the highest level $5 \mathrm{~min}$ after infusion and quickly returned to baseline values, which suggests that either the response was delayed in the rumen epithelium cells or a functional change occurred in existing rumen epithelial cells. Alternatively, butyrate that has not been used by enterocytes is transported by the portal vein to the liver where it is readily metabolized as has been found in other animal species including humans (Bloemen et al., 2009) and rats (Demigné et al., 1986). On the other hand, plasma BHB increased to the highest level 15 min after infusion except for 0B. The increase in plasma BHB may be related to slow rumen butyrate metabolism, which would agree with previous findings in which cows were pulse-infused with different levels of butyrate (Herrick et al., 2017). It is also possible that the maximum pulse-dose used in our study (1.52 g of sodium butyrate/kg of BW) could be too high for rumen microorganisms to adapt faster. In agreement with this, Herrick et al. (2017) suggested that a ruminal pulse-dose infusion of $1.29 \mathrm{~g}$ of sodium butyrate $/ \mathrm{kg}$ of $\mathrm{BW}$ is the maximum threshold concentration in cows.

Our data also show that total secreted insulin was found to be closely correlated with the butyrate dose infused and ruminal butyrate, suggesting that butyrate absorbed from the rumen into rumen epithelial cells is may act on pancreatic $\beta$ cells, because VFA receptors are known to co-exist in pancreatic $\beta$ cells (Priyadarshini et al., 2016). Furthermore, the apparent increase in insulin following infusion of butyrate (reaching a 14fold increase) is in agreement with results reported from other studies in ruminants (Horino et al., 1968; Neogrady et al., 1989; Sano et al., 1995; Herrick et al., 2017). These authors concluded that butyrate might have a physiological role in controlling insulin secretion, suggesting that butyrate could stimulate insulin secretion through a direct effect on pancreatic $\beta$-cells. Also, we found a positive correlation between plasma concentration of GLP-1 and insulin. Consistent with this, it has been reported that GLP-1 is an insulinotropic gut hormone (Schmidt et al., 1985; Fehmann and Göke, 1997). Therefore, it is possible that the elevated plasma concentration of GLP-1 partially contributed to enhance insulin secretion.

\section{CONCLUSIONS}

Under the described experimental conditions the present findings demonstrated that pulse-dose intraruminal butyrate infusion affected GLP-1 and GLP-2 marginally. In particular, there were smaller changes in GLP-2 than expected when considering change relative to baseline. However, insulin, ruminal, and plasma butyrate release increased by butyrate. No correlation was found between BHB and GLP-1 or GLP-2, which is incompatible with the speculations of earlier studies in calves and other animal species. The use of either protected butyrate or a direct infusion of butyrate into the duodenum may provide a better understanding of the molecular mechanisms by which butyrate interacts with proglucagon to stimulate GLP-1 and GLP-2 release.

\section{ACKNOWLEDGMENTS}

The authors express sincere gratitude to Natural Sciences and Engineering Research Council of Canada (NSERC), Alberta Milk (Edmonton, Canada), and Pancosma (Geneva, Switzerland) for funding this project. The authors thank M. Steele's laboratory team members for helping during sample collection. The assistance and expertise of Brenda Tchir (University of Alberta, Edmonton, Canada) is also greatly valued. We also thank Masahito Oba (University of Alberta) for useful discussion prior to planning of this study.

\section{REFERENCES}

Baldassano, S., A. Amato, and F. Mulè. 2016. Review: Influence of glucagon-like peptide 2 on energy homeostasis. Peptides 86:1-5.

Bloemen, J. G., K. Venema, M. C. Van de Poll, S. W. Olde Damink, W. A. Buurman, and C. H. Dejong. 2009. Short chain fatty acids exchange across the gut and liver in humans measured at surgery. Clin. Nutr. 28:657-661.

Brooks, L., A. Viardot, A. Tsakmaki, E. Stolarczyk, J. K. Howard, P. D. Cani, A. Everard, M. L. Sleeth, A. Psichas, J. Anastasovskaj, J. D. Bell, K. Bell-Anderson, C. R. Mackay, M. A. Ghatei, S. R. Bloom, G. Frost, and G. A. Bewick. 2016. Fermentable carbohydrate stimulates FFAR2-dependent colonic PYY cell expansion to increase satiety. Mol. Metab. 6:48-60.

Burrin, D. G., B. Stoll, and X. Guan. 2003. Glucagon-like peptide 2 function in domestic animals. Domest. Anim. Endocrinol. 24:103122.

Connor, E. E., C. M. Evock-Clover, M. P. Walker, T. H. Elsasser, and S. Kahl. 2015. Comparative gut physiology symposium: Comparative physiology of glucagon-like peptide-2: Implications and applications for production and health of ruminants. J. Anim. Sci. 93:492-501.

Connor, E. E., C. M. Evock-Clover, E. H. Wall, R. L. Baldwin, M. Santin-Duran, T. H. Elsasser, and D. M. Bravo. 2016. Glucagonlike peptide 2 and its beneficial effects on gut function and health in production animals. Domest. Anim. Endocrinol. 56:S56-S65.

Connor, E. E., S. Kahl, T. H. Elsasser, R. L. Baldwin VI, R. Fayer, M. Santin-Duran, G. L. Sample, and C. M. Evock-Clover. 2013. 
Glucagon-like peptide 2 therapy reduces negative effects of diarrhea on calf gut. J. Dairy Sci. 96:1793-1802.

Connor, E. E., E. H. Wall, D. M. Bravo, C. M. Evock-Clover, T. H. Elsasser, R. L. Baldwin, M. Santín, B. T. Vinyard, S. Kahl, and M. P. Walker. 2017. Reducing gut effects from Cryptosporidium parvum infection in dairy calves through prophylactic glucagonlike peptide 2 therapy or feeding of an artificial sweetener. J. Dairy Sci. 100:3004-3018.

Deacon, C. F., M. A. Nauck, M. Toft-Nielsen, L. Pridal, B. Willms, and J. J. Holst. 1995. Both subcutaneously and intravenously administered glucagon-like peptide-1 are rapidly degraded from the $\mathrm{NH}_{2}$-terminus in type II diabetic patients and in healthy subjects. Diabetes 44:1126-1131.

Demigné, C., C. Yacoub, and C. Rémésy. 1986. Effects of absorption of large amounts of volatile fatty acids on rat liver metabolism. J. Nutr. 116:77-86.

Dijkstra, J., H. Boer, J. Van Bruchem, M. Bruining, and S. Tamminga. 1993. Absorption of volatile fatty acids from the rumen of lactating dairy cows as influenced by volatile fatty acid concentration, $\mathrm{pH}$ and rumen liquid volume. Br. J. Nutr. 69:385-396.

Drucker, D. J. 2002. Biological actions and therapeutic potential of the glucagon-like peptides. Gastroenterology 122:531-544.

Drucker, D. J., and B. Yusta. 2014. Physiology and pharmacology of the enteroendocrine hormone glucagon-like peptide- 2 . Annu. Rev. Physiol. 76:561-583.

Elsabagh, M., Y. Inabu, T. Obitsu, and T. Sugino. 2017. Response of plasma glucagon-like peptide-2 to feeding pattern and intraruminal administration of volatile fatty acids in sheep. Domest. Anim. Endocrinol. 60:31-41.

Fehmann, H. C., and B. Göke. 1997. The insulinotropic gut hormone glucagon-like peptide-1. Pages I-VII in Front Diabetes. Vol. 13. H. C. Fehmann and B. Göke, ed. Karger International, Basel, Switzerland.

Gao, Z., J. Yin, J. Zhang, R. E. Ward, R. J. Martin, M. Lefevre, W. T. Cefalu, and J. Ye. 2009. Butyrate improves insulin sensitivity and increases energy expenditure in mice. Diabetes 58:1509-1517.

Górka, P., Z. M. Kowalski, P. Pietrzak, A. Kotunia, R. Kiljanczyk, J. Flaga, J. J. Holst, P. Guilloteau, and R. Zabielski. 2009. Effect of sodium butyrate supplementation in milk replacer and starter diet on rumen development in calves. J. Physiol. Pharmacol. 60:47-53.

Górka, P., P. Pietrzak, A. Kotunia, R. Zabielski, and Z. M. Kowalski. 2014. Effect of method of delivery of sodium butyrate on maturation of the small intestine. J. Dairy Sci. 97:1026-1035.

Górka, P., B. Śliwiński, J. Flaga, J. Wieczorek, M. M. Godlewski, E. Wierzchoś, R. Zabielski, and Z. M. Kowalski. 2017. Effect of butyrate infusion into the rumen on butyrate flow to the duodenum, selected gene expression in the duodenum epithelium, and nutrient digestion in sheep. J. Anim. Sci. 95:2144-2155.

Guilloteau, P., G. Savary, Y. Jaguelin-Peyrault, V. Romé, L. Le Normand, and R. Zabielski. 2010. Dietary sodium butyrate supplementation increases digestibility and pancreatic secretion in young milk-fed calves. J. Dairy Sci. 93:5842-5850.

Hartmann, B., M. B. Harr, P. B. Jeppesen, M. Wojdemann, C. F. Deacon, P. B. Mortensen, and J. Holst. 2000. In vivo and in vitro degradation of glucagon-like peptide-2 in humans. J. Clin. Endocrinol. Metab. 85:2884-2888.

Herrmann,, C, R. Goke, G. Richter, H. C. Fehmann, R. Arnold, and B. Göke. 1995. Glucagon-like peptide-1 and glucose-dependent insulin-releasing polypeptide plasma levels in response to nutrients. Digestion 56:117-126.

Herrick, K. J., A. R. Hippen, K. F. Kalscheur, D. J. Schingoethe, D. P. Casper, S. C. Moreland, and J. E. van Eys. 2017. Singledose infusion of sodium butyrate, but not lactose, increases plasma $\beta$-hydroxybutyrate and insulin in lactating dairy cows. J. Dairy Sci. 100:757-768.

Horino, M., L. J. Machlin, F. Hertelendy, and D. M. Kipnis. 1968. Effect of short-chain fatty acids on plasma insulin in ruminant and non-ruminant species. Endocrinology 83:118-128.

Husveth, F., C. Szegleti, and Z. Neogrady. 1996. Infusion of various short chain fatty acids causes different changes in the blood glu- cose and insulin concentrations in growing lambs deprived of food overnight. J. Vet. Med. A Physiol. Pathol. Clin. Med. 43:437-444.

Inabu, Y., A. Saegusa, K. Inouchi, S. Koike, M. Oba, and T. Sugino. 2017. Plasma concentrations of glucagon-like peptide 1 and 2 in calves fed calf starters containing lactose. J. Dairy Sci. 100:93619371.

Karaki, S. I., R. Mitsui, H. Hayashi, I. Kato, H. Sugiya, T. Iwanaga, J. B. Furness, and A. Kuwahara. 2006. Short-chain fatty acid receptor, GPR43, is expressed by enteroendocrine cells and mucosal mast cells in rat intestine. Cell Tissue Res. 324:353-360.

Karaki, S. I., H. Tazoe, H. Hayashi, H. Kashiwabara, K. Tooyama, Y. Suzuki, and A. Kuwahara. 2008. Expression of the short-chain fatty acid receptor, GPR43, in the human colon. J. Mol. Histol. 39:135-142.

Kotunia, A., J. Wolinski, D. Laubitz, M. Jurkowska, V. Rome, P. Guilloteau, and R. Zabielski. 2004. Effect of sodium butyrate on the small intestine development in neonatal piglets feed by artificial sow. J. Physiol. Pharmacol. 55:59-68.

Kowalski, Z. M., P. Górka, J. Flaga, A. Barteczko, K. Burakowska, J. Oprządek, and R. Zabielski. 2015. Effect of microencapsulated sodium butyrate in the close-up diet on performance of dairy cows in the early lactation period. J. Dairy Sci. 98:3284-3291.

Lesmeister, K. E., and A. J. Heinrichs. 2004. Effects of corn processing on growth characteristics, rumen development, and rumen parameters in neonatal dairy calves. J. Dairy Sci. 87:3439-3450.

Lin, H. V., A. Frassetto, E. J. Jr, A. R. Kowalik, M. M. Nawrocki, and M. M. Lu. 2012. Butyrate and propionate protect against diet-induced obesity and regulate gut hormones via free fatty acid receptor 3-independent mechanisms. PLoS One 7:e35240. https:// doi.org/10.1371/journal.pone.0035240.

Littell, R. C., G. A. Milliken, W. W. Stroup, R. D. Wolfinger, and O. Schabenberger. 2006. SAS for Mixed Models. 2nd ed. SAS Institute Inc., Cary, NC.

Little, T. J., A. N. Pilichiewicz, A. Russo, L. Phillips, K. L. Jones, M. A. Nauck, J. Wishart, M. Horowitz, and C. Feinle-Bisset. 2006 Effects of intravenous glucagon-like peptide-1 on gastric emptying and intragastric distribution in healthy subjects: Relationships with postprandial glycemic and insulinemic responses. J. Clin. Endocrinol. Metab. 91:1916-1923.

Mazzoni, M., M. Le Gall, S. De Filippi, L. Minieri, P. Trevisi, J. Wolinski, G. Lalatta-Costerbosa, J. P. Lalles, P. Guilloteau, and P. Bosi. 2008. Supplemental sodium butyrate stimulates different gastric cells in weaned pigs. J. Nutr. 138:1426-1431.

Neogrady, Z., P. Galfi, and F. Kutas. 1989. Effect of intraruminal butyrate infusion on the plasma insulin level in sheep. Acta Vet. Hung. 37:247-253.

Orskov, C., J. J. Holst, S. Knuhtsen, F. G. Baldissera, S. S. Poulsen, and O. V. Nielsen. 1986. Glucagon-like peptides GLP-1 and GLP2 , predicted products of the glucagon gene, are secreted separately from pig small intestine but not pancreas. Endocrinology 119:1467-1475.

Priyadarshini, M., B. Wicksteed, G. E. Schiltz, A. Gilchrist, and B. T. Layden. 2016. SCFA Receptors in pancreatic Beta cells: Novel diabetes targets? Trends Endocrinol. Metab. 27:653-664.

Rowland, K. J., and P. L. Brubaker. 2011. The "cryptic" mechanism of action of glucagon-like peptide-2. Am. J. Physiol. Gastrointest. Liver Physiol. 301:G1-G8.

Sano, H., S. Tano, H. Takahashi, and Y. Terashima. 1995. Dose response of plasma insulin and glucagon to intravenous n-butyrate infusion in sheep. J. Anim. Sci. 73:3038-3043.

Schmidt, W. E., E. G. Siegel, and W. Creutzfeldt. 1985. Glucagon-like peptide-1 but not glucagon-like peptide-2 stimulates insulin release from isolated rat pancreatic islets. Diabetologia 28:704-707.

Sigalet, D. L., E. de Heuvel, L. Wallace, E. Bulloch, J. Turner, P. W. Wales, P. Nation, P. R. Wizzard, B. Hartmann, M. Assad, and J. J. Holst. 2014. Effects of chronic glucagon-like peptide-2 therapy during weaning in neonatal pigs. Regul. Pept. 188:70-80.

Sugino, T., Y. Hasegawa, Y. Kurose, M. Kojima, K. Kangawa, and Y. Terashima. 2004. Effects of ghrelin on food intake and neuroendocrine function in sheep. Anim. Reprod. Sci. 82-83:183-194. 
Takahashi, T. 2012. Mechanism of interdigestive migrating motor complex. J. Neurogastroenterol. Motil. 18:246-257.

Tavares, W., D. J. Drucker, and P. L. Brubaker. 2000. Enzymatic- and renal-dependent catabolism of the intestinotropic hormone glucagon-like peptide-2 in rats. Am. J. Physiol. Endocrinol. Metab. 278:E134-E139.

Taylor-Edwards, C. C., D. G. Burrin, J. J. Holst, K. R. McLeod, and D. L. Harmon. 2011. Glucagon-like peptide-2 (GLP-2) increases small intestinal blood flow and mucosal growth in ruminating calves. J. Dairy Sci. 94:888-898.

Taylor-Edwards, C. C., D. G. Burrin, N. B. Kristensen, J. J. Holst, K. R. McLeod, and D. L. Harmon. 2012. Glucagon-like peptide-2 (GLP-2) increases net amino acid utilization by the portal drained viscera of ruminating calves. Animal 6:1985-1997.

Thymann, T., I. Le Huërou-Luron, Y. M. Petersen, M. S. Hedemann, J. Elinf, B. B. Jensen, J. J. Holst, B. Hartmann, and P. T. Sangild. 2014. Glucagon-like peptide 2 treatment may improve intestinal adaptation during weaning. J. Anim. Sci. 92:2070-2079. van Niekerk, J. K., M. Middeldorp, and M. A. Steele. 2018. Technical note: The development of a methodology for ruminal and colon tissue biopsying of young Holstein dairy calves. J. Dairy Sci. 101:7212-7218.

Vidrine, K., J. Ye, R. J. Martin, K. L. McCutcheon, A. M. Raggio, C. Pelkman, H. A. Durham, J. Zhou, R. N. Senevirathne, C. Williams, F. Greenway, J. Finley, Z. Gao, F. Goldsmith, and M. J. Keenan. 2014. Resistant starch from high amylose maize (HAMRS2) and dietary butyrate reduce abdominal fat by a different apparent mechanism. Obesity (Silver Spring) 22:344-348.

Wallis, K., J. R. F. Walters, and A. Forbes. 2007. Review article: Glucagon-like peptide 2-Current applications and future directions. Aliment. Pharmacol. Ther. 25:365-372.

Wettergren, A., B. Schjoldager, P. E. Mortensen, J. Myhre, J. Christiansen, and J. J. Holst. 1993. Truncated GLP-1 (proglucagon 78-107-amide) inhibits gastric and pancreatic functions in man. Dig. Dis. Sci. 38:665-673. 